\title{
Design of Teaching Mode under the Perspective of Flipped Classroom-- On the Course of Project Management
}

\author{
Le PEI \\ Management College of Bohai University, Jinzhou, China \\ p982262@126.com
}

Keywords: Flipped classroom, Project management, Teaching mode.

\begin{abstract}
Internet innovation brings flipped classroom mode which has new ideas and positive influences. The teaching mode should be designed scientifically to fuse flipped classroom into teaching process smoothly, to get better teaching effects. The inspection should be made from facets of courses, technologies, students and teachers. The students need more options to inspire interests of active learning. The cooperative learning will be probed. In the operation, multiple system should be constructed, which includes teaching objectives and knowledge points, environmental control, technical supports, and relationships between teachers and students. The focuses are design of teaching procedures and integrated total process evaluation.
\end{abstract}

\section{Introduction}

Pushed by the development information technology and popularization of information equipment, internet combined with education quickly. As an important outcome, flipped classroom is impacting and changing traditional education modes and methods. The core idea of flipped classroom is that using video websites, instant messaging tools and other education resources to reconstruct and optimize education process guided by mission. Then, students have more personal study choices; the interests of probing knowledge also will be inspired. The theory education widen out of classroom, students can search and gain knowledge anytime and anywhere by mini video, internet classroom, and so on. Communication, collaboration, share and discussion between teacher and student, student and student are concentrated in classroom. Verification and research of knowledge will be accomplished through situation simulation, case analysis, experiment, question answering, and so on. Flipped classroom strengthens frequency and depth of interaction, improves efficiency of knowledge assimilation and internalization. Compared with traditional mode, flipped classroom has more advantages in aspects of study autonomy, teamwork, creative spirit, classroom atmosphere, knowledge internalization.[1]

\section{The Cardinal Principles of Flipped Classroom Mode Design of Project Management Course}

\section{The Course}

According to the project management body of knowledge, the course includes introduction, organizational influences and project life cycle, project management processes, project integration management, project scope management, project time management, project cost management, project quality management, project human resource management, project communications management, project risk management, project procurement management, and project stakeholder management. The teaching link may be divided into three sectors: pre-course, course, post-course. The focus of pre-course is knowledge preparation by watching video, electronic handouts, and cases. The focus of course is knowledge assimilation and internalization by team competition and teachers' guidance. The focus of post-course is knowledge expansion by teamwork and course task.

The design of teaching mode lays stress on practice of essential theories and methods. Situation simulation, case analysis, and teamwork are used to strengthen interaction. Based on course characteristics and study ability, the course structure and course videos should be constructed scientifically. That customized course objectives and scope of self-study knowledge should be 
provided to improve efficiency of class teaching. Students should be guided in study plans. The performances of individual, team, and class should get timely evaluation and feedback.

\section{The Technique}

The course is important part of college plan, and it should get resource and support from college. The course should match with college, teacher, and student, to gain better education outcome.[2] The percentage of flipped classroom, which may change, is decided by the differentiation of course nature, knowledge constitution, and teaching process. It should be avoided that too much activities in outside course, and students have not enough ability and energy to cope. The percentage of flipped classroom about simple, repeatable and procedural activity should be lower, such as copy, reappear of knowledge. Teachers may control students' practice by course supervision and project guidance. The percentage of flipped classroom about complicated, exploratory, creative should be higher. Teachers inspire students' interest and enthusiasm by course interaction and question answering.

The mainstream information technology breaks down the restriction of study time and spot. Students get more flexible chances of learning style. The study resource and interaction platform is necessary, which can be added into online video, electronic handouts, question bank, study forum, and so on. High quality resources will be integrated and shared in the platform to avoid waste and chaos. Students may have less difficulty and cost in searching related resource than before. More time can be used in knowledge digestion and absorption. Teachers select and update teaching resource from and for the platform to avoid knowledge outdated. More time can be used to focus on teaching points, simplify knowledge difficult points, and supervise students' progress outside course.

\section{The Student}

The psychology condition, learning mode, and receive ability of knowledge of all the students should be researched. The outside course task and occupation time must conform to the rule of growth. The satiation of information equipment owned and used by students should be investigated to avoid technical misuse and information gap affecting knowledge learning and personality cultivation. Students should be trained to use study resource and interaction platform to get what they need. There are also evaluations, such as course examination, self-test, review questions on knowledge points.

The amount of students in project management course should be under 40 , the amount of project team should be under 8 . The suit amount of project team to interact is 6 . Each project team should build its management regulations and assign task to its number to guarantee effective participation. Teaching and learning may be designed several phases. At the end of each phase, outputs and deliverables should be checked. The learning progress and result of each team may be differentiated and sorted, which will be presented in the course to spur and impel students. Team number may transfer to other team who is willing to receive him/her. Because learning progress of team is different, learning ability of student is different. He or she should find out the suitable one to match each other. Whatever in fast or slow, the aim is to satisfy students' diverse need, to help them grasp and apply knowledge on project management better.

\section{The Teacher}

Flipped classroom demands teacher to innovate idea, role, and method. At the same time, they should promote their quality and ability to become a node connecting environment, technology and students. Flipped classroom makes traditional centralized learning into distributed coordination learning, makes teacher from organizer and manager into supporter and guider. Teachers may adjust teaching process and method after they know well students and their difference in learning ability. Modern information tool and technology will help students and teachers understand and grasp course and knowledge points. Flexible teaching mode makes project management body of knowledge more easy to be received than ever before.

That the relationship of teaching inside and outside course, between teachers and students, between students and students, between cooperation and competition of project teams should be balanced. The relationship mode should be multiple, harmony. Under the presser of teaching, research and cultivation, teachers can't make allowance for too much courses of flipped classroom mode at the 
same time. Compared with traditional teaching mode, college should provide more supports, which include time, equipment, technology and fund, to handle relationship of courses and teachers, to create suitable atmosphere for flipped classroom teaching mode.

\section{The System Constitute of Flipped Classroom Mode of Project Management Course}

\section{Teaching Objectives and Knowledge Points}

The total teaching aim of project management course is that making students be familiar with essential theories of project management, understand rules of project operation, and grasp common tools and methods in project process to solve ordinary problems. When students learn project management theories and professional techniques, they should promote abilities of practice and communication, integrate and expand related knowledge to get complex output. On the base of whole project management body of knowledge, the teaching units and key knowledge points can be divided into 10 modules. These modules are:

(1)Project organization and management process: stakeholders and management of their relationship, project organization structure, role and responsibility of a project manager, project life cycle, project management process, etc.

(2)Project integration management: develop project charter, develop project management plan, direct and manage project execution, monitor and control project work, perform integrated change control, close project or phase, etc.

(3)Project scope management: collect requirement, define scope, create WBS, verify scope, control scope, etc.

(4)Project time management: define activities, sequence activities, estimate activity resources, estimate activity durations, develop schedule, control schedule, etc.

(5)Project cost management: estimate costs, determine budget, control costs, etc.

(6)Project quality management: plan quality, perform quality assurance, perform quality control, etc.

(7)Project human resource management: develop human resource plan, acquire project team, develop project team, manage project team, etc.

(8)Project communications management: identify stakeholders, plan communications, distribute information, manage stakeholder expectations, report performance, etc.

(9)Project risk management: plan risk management, identify risk, perform qualitative risk analysis, perform quantitative risk analysis, plan risk responses, monitor and control risks, etc.

(10)Project procurement management: plan procurements, conduct procurements, administer procurements, close procurements, etc.

\section{Control of Environment}

According to needs of teaching objectives and learning contents, multiple flexible course environments should be created to break down the restriction of time and spot to reinforce interaction. Meanwhile, to avoid deviation and laziness, the environment should be under control. The teaching tools and learning resources should be selected and managed scientifically. To supervise the performance of project teams inside and outside course, they should be authorized hierarchically in the team and among teams.

As to outside course environment, it should be based on campus network, then expand and enrich teaching and learning resources. Teaching video, electronic handouts, online question bank, and learning forum suited to the course and students should be integrated and optimized. Beside project management, other courses should be designed totally and systematically. Interrelated courses and knowledge will combine dispersive resources into a whole. Numbers of project teams work together on outside course learning schedule and project task, which will be examined by teachers to balance the progress of course and teams. Students and teams may test themselves through learning platform to evaluate performance. The consequence will be filed by teachers. 
As to inside course environment, teachers provide more choices and independence to students by judgment and support. In operation, different plans and courseware can be used at the same time to make teaching resource more multivariate. During the course, communications on project management practices should be emphasized. Teaching lecture less, student-student and student-teacher inside and among teams interact more. Project teams report and sum up progress of learning and work according to schedule. Their demands and questions will be responded and guided by teachers. The written examination could be replaced by integrated whole process evaluation on knowledge points, teamwork and learning performance. The course is a necessary part of socialization for students. But in cases, it is possible for students communicate and grasp knowledge through remote system, not on spot.

\section{Support of Technology}

New resource and technology together push the extending and deepening of project management course. Fundamental resource and infrastructure should be managed by college, coordinated and assigned among courses, including campus network, resource bank, classroom, library, etc. There should be full-time administer, who manages network and forum, maintains teaching, learning and test system, assists making online video and questions bank. Plenty use of multimedia inspires learning motivation and interest. Delicate teaching videos ensure flipped classroom. Self-learning and cooperative learning will be principal method.[3] In teaching process, point redemption scheme will promote positive competition among project teams, the winner will get reward. Students may take part in scenario simulation and real project, or social experiment to get direct experience. Modern evaluation idea and technique should be introduced in whole learning process of student and team to ensure facticity and accurateness.

With the population of intelligent mobile phone and wireless equipment, the upgrade of smart campus and infrastructure, it is essential for college to provide WiFi and equipment to students for free or at a low price to decrease learning cost and break down technology restrict of online learning. College should increase information quality and ability of students, help them to form right information usage habit and acquisition mode to suit for new teaching and learning mode. The project management information platform and professional software should stimulate enterprise's real function and procession. Students should be familiar with situation and usage method of mainstream project management software. P3 (Primavera), Artemis Viewer (Artemis), Open Work Bench (NIKU) are facing large project and company. Project Scheduler (Sciforma), Sure Trak (Primavera), Project (Microsoft), Turbo Project (IMSI) are facing medium and small project and company.[4] Simulation formula competitive game software will also be introduced into project management course to make it more interesting.

\section{Relationship between Student and Teacher}

Student and teacher should cultivate learning culture together, and innovate their roles in flipped classroom. Student is the major actor in flipped classroom mode of project management course. They can take part in in design and implement of teaching and learning to become real participator and questioner. The functions of teacher convert from lecturing and managing to leading, inspiring, motivating, supporting and explaining. For diverse learning needs and interests of students, teachers should integrate and expand the scope of knowledge, update and add knowledge reserve, mine implicit knowledge. If possible, teacher may guide student and team in research on project.

Interaction and communication exist in student-teacher, student-student, team-student, team-team. Communication may be formal or informal, regular or irregular. Students and teachers work together on task list, learning and activity plan to ensure consistency and avoid deviation. More autonomy and option will bring student more identification and belongingness to the team. It predicted that efficiency and performance of cooperative learning will be higher. Fluent and effective communication balances the decentralization of learning time and spot and the continuity of learning process and body of knowledge to prevent knowledge fragmentation. The actors of student, teacher and team share resource, promote ability. Beside, supervision and guidance is necessary for high learning quality. 


\section{The Operation Process of Flipped Classroom Mode of Project Management Course}

\section{Teaching Process Solution}

The idea of compound teaching and learning, which leading optimize and restructure teaching and learning process inside and outside course, focus on student's learning behavior in flipped classroom. Self-learning and cooperative learning are priority outside course based on task. Researching learning supported by teacher is priority inside course. Pre-course, course and post-course connected with each other. The knowledge unit is divided into understand/experience phase, verify/apply phase, and expand/create phase. In understand/experience phase, students use learning resources in platform around learning object of unit module, search their interest in wider field to accomplish memory and understand of knowledge. In verify/apply phase, students analyze and internalize knowledge, grasp constitute of theory and operation method, verify their authenticity and reliability, evaluate the knowledge in application. In expand/create phase, students digest and absorb knowledge, integrate course and related knowledge into a total structure, create new knowledge and expand body of knowledge finally. These phases connect with each other as a whole. The understand/experience phase occurs in pre-course and course. The verify/apply phase occurs in course, pre-course, post-course. The expand/create phase occurs in post-course and course.

The teaching of project management course is around teaching task and project procession, emphasizes on combination of self-learning and cooperative learning, harmony development of all the teams. The concrete sectors consist of task arrangement, team build, collaborative research, achievement demonstration, question and answer, summary and file. In the sector of task arrangement, that declarative knowledge, procedural knowledge and tacit knowledge should be distinguished. The focus on declarative knowledge is understood precisely. The focus on procedural knowledge is handled standardly. The focus on tacit knowledge is realized deeply. In the sector of team build, teacher evaluates the number and structure of team after team combination. Second chance to change team will be given to students. In the sector of collaborative research, every team number should participate in learning. They should take suitable responsibility in project. Teams could share resources and ideas. In the sector of achievement demonstration, students present their learning and practice experience to report the implementation process of achievement. In the sector of question and answer, multiple interactions are encouraged. Students ask, teachers answer. Teachers ask, students answer. Students ask, students answer. On the base of feedback, teachers may help students to grasp knowledge and practice, even optimize teaching and learning procession. In the sector of summary and file, key knowledge points should be emphasized systematically to cover all the body of knowledge. Teachers, students and teams should save data and file produced in procession to provide proof and material for phase and final evaluation.

\section{Integrated Whole Process Evaluation}

Learning dimension theory proposes that the evaluation dimensions of teaching include motion dimension, content dimension and interaction dimension from the view of learning.[5] In integrated whole process evaluation, the assessment system focus on ability, and evaluation indicators should be explicit, precise and operational. Evaluation indicators consist of learning attitude, team work, technical skill, operation criterion, performance and achievement covers all the phases of pre-course, course and post-course. The forms of evaluation include self-evaluation, mutual evaluation and examination to ensure objective, just and scientific. For the student is principal actor, self-evaluation and mutual evaluation should have more weighting. As self-evaluation, students may test themselves by online questions bank. As mutual evaluation, students in the same project team evaluate others on learning and project work, and team evaluate other teams on project operation. As examination, there are formal examinations, also informal test, such teachers put questions and answer students' questions.

In view of features of project management course, the efficiency of cooperation and quality of learning should be under control. It should be grid performance evaluation mode. There should be not only transverse compare of team numbers, but also longitudinal compare of number's growth. There should be not only transverse compare of teams, but also longitudinal compare of project operation. 
That course teaching plan, learning plan and team work plan should be designed appropriately. The files, such as learning note, video, work weekly note, will record the condition of learning and work of individual and team. The teaching and learning resource and interaction platform ensures timely and effective communication among student, teacher and team. Task assignment and cooperation in team will be guided. Everyone may get operation and process information. Deviations will be prevented and corrected to achieve multiple objectives of individual and team, teaching, learning and work.

\section{Summary}

In the background of "Internet +", mode of project management course is re-locating and re-constructing. The Course, technique, student, teacher and college combine into a whole to accomplish learning and teaching aims, which is more flexible and tight than ever. That teaching objectives and knowledge points, control of environment, support of Technology, relationship between student and teacher, constitute the fatal facets of the system of flipped classroom mode of project management course. Assisted by modern technique, the integrated whole process evaluation supervises the design and implementation of teaching process to guarantee the quality and efficiency of teaching and learning.

\section{References}

[1] Chao-yang He, Ou Yu-fang, Cao Qi, Inspiration of USA Universities' Inverted Classroom Teaching Model, Research on High Engineering Education. 2 (2014):148-151.

[2] Xing-long Zhao, The Design of Teaching Mode Based on Knowledge Construction in Flipped Classroom, Research on Modern Remote Education. 2 (2014):55-61.

[3] Bing-chao Pan, Quasi-experimental Study on Flipped Classroom's Impact on the University Teaching Effect, Modern Education Technology. 12 (2014):84-91.

[4] Jing-jing Wang, Experimental Teaching of Project Management, Experimental Technology and Management. 3 (2011):256-258.

[5] Knud Illeris, How We Learn, Beijing: Education Science Press. 2010:23-30. 